J. Lake Sci. (湖泊科学), 2020, 32(5): 1396-1405

DOI 10. 18307/2020. 0513

(c) 2020 by Journal of Lake Sciences

\title{
富营养化湖库天一空一地一体化监控平台系统设计与实践”
}

\author{
段洪涛 $1^{* *}$, 万能胜 ${ }^{2}$, 邱银国 ${ }^{1}$, 刘 刚 $^{3}$, 陈 青 $^{1}$, 罗菊花 ${ }^{1}$, 陈 远 $^{1}$, 齐天赐 ${ }^{1}$ \\ ( 1 : 中国科学院南京地理与湖泊研究所中国科学院流域地理学重点实验室,南京 210008) \\ (2: 安徽省巢湖管理局湖泊生态环境研究院,合肥 230000) \\ (3:巢湖管理局环境保护监测站,巢湖 238000)
}

摘 要: 湖泊和水库是我国的主要饮用水源地, 但大都处于富营养化状态, 蓝藻水华频发, 已成为影响社会稳定、制约区 域社会经济可持续发展的重大问题. 蓝藻水华的整体应对策略, 已经从被动应急转变为主动防御; 但要做到主动防御, 必 须有现代化全方位的蓝藻灾害监测监控手段和体系, 及时掌握蓝藻水华及其衍生灾害现状和动向, 在未发生或者刚发生 时及时觉察. 本文针对富营养化湖库富营养化引起的蓝藻水华应急监控问题, 按照 “整个湖体、重点区域、关键位置” 3 个 监测层次,利用中高分辨率卫星、无人机、岸基/平台视频、自动浮标、人工巡测等技术或手段,围绕“现状掌握、异常报警、 原因追溯” 的建设目标, 提出了天一空一地一体化监控系统建设框架, 明确了不同手段的协同方式和业务流程, 并正在巢 湖进行应用实践. 相信本文提出的系统架构不仅在巢湖,在更多的富营养化湖库都具有重要的应用和推广价值.

关键词: 湖泊; 水库;巢湖;蓝藻水华;系统平台;应急监测

\section{Discussions and practices on the framework of monitoring system in eutrophic lakes and reservoirs*}

DUAN Hongtao $^{1 * *}$, WAN Nengsheng ${ }^{2}$, QIU Yinguo ${ }^{1}$, LIU Gang ${ }^{3}$, CHEN Qing $^{1}$, LUO Juhua ${ }^{1}$, CHEN Yuan ${ }^{1}$ \& QI Tianci ${ }^{1}$

(1: Key Laboratory of Watershed Geographic Sciences, Nanjing Institute of Geography and Limnology, Chinese Academy of Sciences, Nanjing 210008, P.R.China)

(2: Institute of Lake Ecology and Environment, Anhui Provincial Lake Chaohu Administration, Hefei 230000, P.R. China)

(3: Environmental Protection Monitoring Station, Anhui Provincial Lake Chaohu Administration, Chaohu 238000, P.R. China)

Abstract: Lakes and reservoirs are the main sources of drinking water in China, but most of them are in the state of eutrophication with frequent cyanobacterial blooms. This has become major issues affecting social sustainability and restricting the local development. The overall response strategy of cyanobacterial blooms must have modern and comprehensive monitoring methods and systems, so as to timely grasp the status and trends of such blooms and their derived disasters. This article aims at the emergency monitoring of cyanobacterial blooms in eutrophic lakes and reservoirs. According to the three monitoring levels of "the entire lake, key areas, and key locations", the current satellite, drone, and shore-based /platform video, buoy, manual inspection and other technologies or methods have proposed the construction goals, system framework, and workflow. These are also applied in the Lake Chaohu. It is believed that this framework of monitoring system proposed in this paper has important application and promotion value not only in Lake Chaohu, but also in more eutrophic lakes and reservoirs.

Keywords: Lake; reservoir; Lake Chaohu; cyanobacteria blooms; system platform; emergency monitoring

湖泊和水库是我国的主要饮用水源地, 但大都处于富营养化状态. 根据 2007-2010 年第二次全国湖泊

* 2020-02-03 收稿; 2020-05-05 收修改稿.

国家水体污染控制与治理科技重大专项 (2017ZX07603-001) 资助.

** 通信作者;E-mail:htduan@ niglas.ac.cn. 
调查结果, 东部平原湖区、东北平原与山地湖区和云贵高原湖区 138 个面积大于 $10 \mathrm{~km}^{2}$ 的湖泊中 $85.4 \%$ 都处 于富营养化水平 ${ }^{[1]}$. 富营养化的一个严重后果就是蓝藻水华频繁暴发, 大量水华蓝藻漂浮在湖面, 水体呈稠 密的油状, 腥臭难忍, 每升藻类密度达到上亿甚至百亿个, 不仅影响水体景观, 还威胁饮用水安全. 事实上, 2007 年无锡太湖水危机事件, 就是由蓝藻水华暴发引起的 ${ }^{[2]}$; 同样, 合肥市因为蓝藻水华问题, 关闭了以西 巢湖为水源地的水厂, 改至水质较好的董铺水库和大房虽水库 (董大水库); 昆明市也因为滇池蓝藻经常性 暴发, 2007 年开通了掌鸠河引水供水工程, 水源地改为云龙水库. 湖泊等水体富营养化引起的蓝藻水华频 发,已成为影响社会稳定、制约区域社会经济可持续发展的重大问题.

在太湖、巢湖和滇池等富营养化湖泊, 蓝藻水华已经成为常态, 并将在未来较长时间内存在. 太湖在连 续 10 年的全流域高投人治污背景下, 2017 年与 2010 年相比,总氮 ( TN) 浓度有所下降,但仍高于 $2.00 \mathrm{mg} / \mathrm{L}$; 总磷 (TP) 浓度轻微下降后又显著升高, 2017 年全湖平均浓度为 $0.13 \mathrm{mg} / \mathrm{L}$, 增高 $16.9 \%$; 叶绿素 $a$ 浓度也有 所升高, 在 $40 \mu \mathrm{g} / \mathrm{L}$ 左右 ${ }^{[3-4]}$. 巢湖管理局环境保护监测站调查数据显示, 巢湖 2019 年 TN 浓度在 $0.82 \sim 1.55$ $\mathrm{mg} / \mathrm{L}$ 之间, 年均值为 $1.18 \mathrm{mg} / \mathrm{L}$; TP 浓度在 $0.050 \sim 0.120 \mathrm{mg} / \mathrm{L}$ 之间, 年均值为 $0.078 \mathrm{mg} / \mathrm{L}$, 全年水质在 $\mathrm{IV}$ 类 上下浮动. 滇池形势也不容乐观, 根据生态环境部最新公布数据 ( http://www. mee.gov.cn/), 滇池 2019 年第 4 季度为重度污染、轻度富营养, 主要污染指标为 $\mathrm{pH}$ 、化学需氧量和 TP 浓度. 而在太湖开展的蓝藻控制试验 结果表明, 蓝藻大量生长需要的最低 TN 和 TP 浓度分别为 1.26 和 $0.082 \mathrm{mg} / \mathrm{L}^{[5]}$. 但是, 目前太湖、巢湖和滇 池营养盐浓度整体上,特别是夏季, 仍然高于该阈值, 蓝藻水华暴发已成为常态 ${ }^{[6-8]}$.

蓝藻水华的整体应对策略, 已经从被动应急转变为主动防御. 要做到主动防御, 必须及时了解蓝藻水华 的现状和动向. 但是湖泊和水库等现有监测手段普遍不完善, 应急监测体系缺乏, 难以满足蓝藻防控与应急 处置要求. 当前, 无人机、视频监控、自动浮标以及高分卫星等技术的不断发展, 为构建富营养化湖库蓝藻 天一空一地协同的立体应急监控体系提供了很好的条件. 实际上, 天一空一地一体化的概念早已提出, 其核心 内容是整合天、空和地基等不同观测手段,聚合分析多源多维异构时空大数据,弥补单一手段观测尺度或维 度的不足, 实现不同手段和信息的协同和互补, 服务应急和决策. 天一空一地立体监控目前已经在数字农业、 大气环境、地震灾害等多种领域应用实践 ${ }^{[9-10]}$, 具体水环境监测领域, 如太湖、千岛湖、滇池、洱海等都提出了 天一空一地立体化监测的理念, 并进行了部分实践. 实际上, 卫星遥感、水质站自动监测等手段早已经被广泛 使用,但更多是各自运行相互独立,部分实现了手段的立体化,但并没有真正实现手段的协同和一体化. 天一 空一地一体化监测并不是单纯地通过增加一两种技术手段来补充形成立体监测网络, 更需要整合不同手段 信息,在空间尺度、时间尺度和获取不同参数信息等方面取长补短、互相补充,做到不同手段信息的协同和 交互. 从这个角度来讲, 目前形成天一空一地一体化监控系统的案例还比较少, 更没形成应用范式方便更大 范围推广. 本文围绕富营养化湖泊蓝藻水华及其衍生灾害,尝试通过充分发挥多源观测手段在不同时、空信 息观测方面的优势, 构建蓝藻水华应急监控系统框架和体系, 形成全方位、多层次的天一空一地一体化观测 和应急防控平台, 防止蓝澡水华引起的水源地危机等突发性灾害发生, 保障湖泊生态系统健康和水源地水 质安全,相信在富营养化湖库具有重要应用和推广价值.

\section{1 系统架构设计}

\section{1 建设目标}

针对富营养化湖库主要水环境灾害——蓝藻水华及其衍生物, 完善监测手段, 构建应急监控体系, 为蓝 藻水华科学管理和应急防控服务. 建设目标整体上可概括为“三三五”: (1) 三个目标: 现状掌握、异常报警、 原因追溯; (2)三个层次:整个湖体、重点区域、关键位置; (3) 五种手段:卫星、无人机、岸基/平台视频、浮标、 人工巡测. 针对现有卫星遥感阴雨天没有数据的问题,补充无人机、岸基/平台视频监控、自动浮标等监测手 段, 实现湖体一重点区域一关键位置全覆盖的天一空一地立体监控, 及时掌握现状信息; 构建富营养化湖库应 急监控平台, 发挥卫星遥感、岸基/平台视频监测和浮标等连续观测特长, 实现水华、水色和水质指标等异常 自动报警, 及时启动人工和无人机等应急监测手段, 形成完善的富营养化湖库蓝藻应急监控体系.

\section{2 系统框架}

富营养化湖库蓝藻监控平台结构包括 3 层: 数据获取层、业务逻辑层以及应用表现层 (图 1).(1) 数据获 

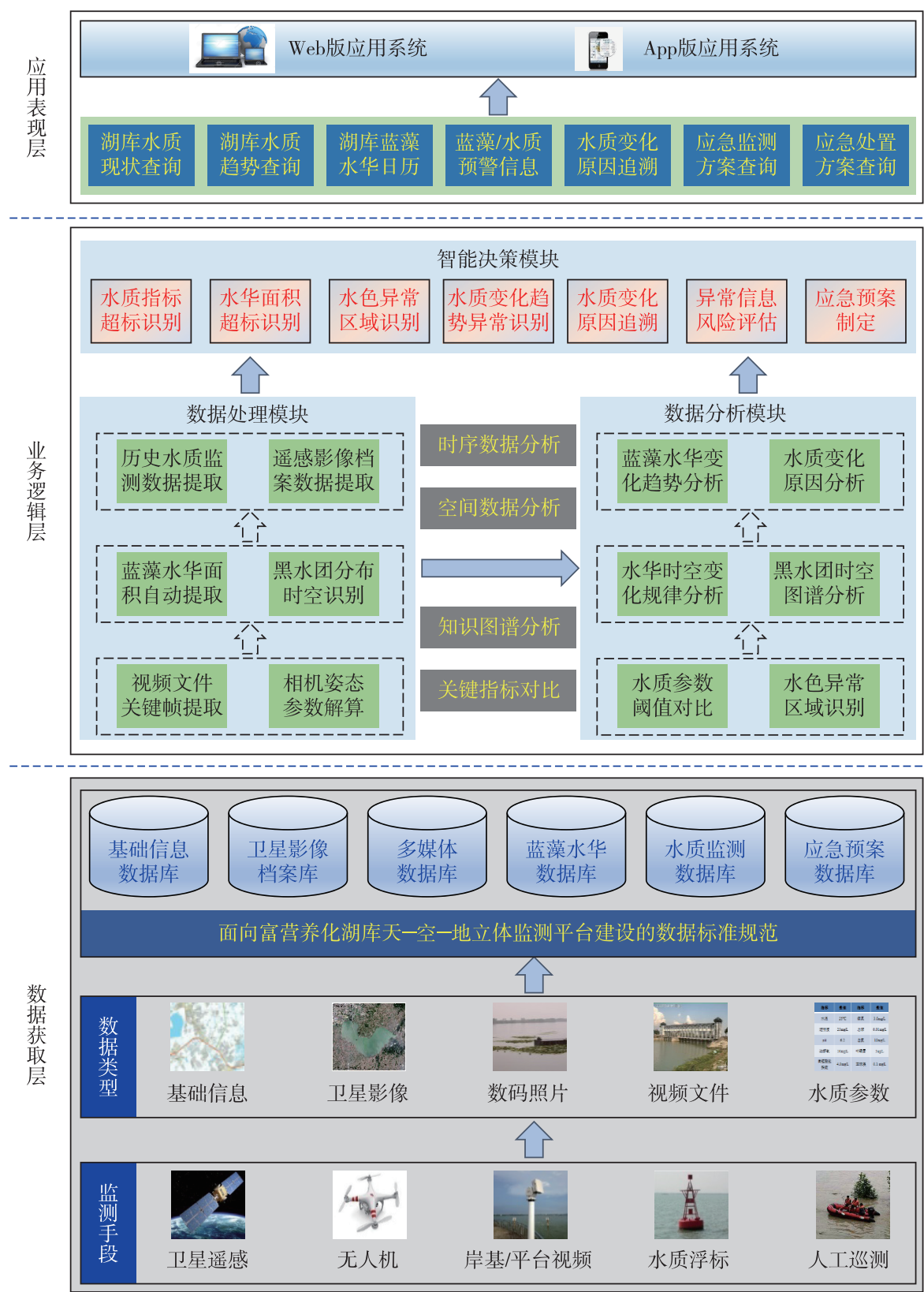

图 1 富营养化湖库蓝藻天一空一地一体化监控平台架构

Fig. 1 Architecture of cyanobacterial blooms monitoring platform in eutrophic lakes

取层: 为系统业务功能的实现与应用提供必要的数据支撑, 基于卫星遥感、无人机、岸基/平台视频、浮标、人 工巡测等监测手段构建天一空一地一体化的湖库蓝藻立体监控网络, 全方位、实时感知湖库水质情况以及异 常信息,并通过多源异构数据的标准化建设实现数据标准化处理, 最终建成标准化时空数据库; (2) 业务逻 辑层:连接后台数据库与平台人机界面的核心,包括数据处理、数据分析以及智能决策 3 个功能模块. 其中, 数据处理模块对多种监测手段获取的监测数据进行预处理, 为数据的对比分析以及系统的智能决策提供支 持; 数据分析模块通过对数据的预处理结果以及历史数据进行分析, 实现水质变化趋势分析与预测、水质/ 
水色异常识别及原因分析等功能;智能决策模块基于数据处理模块、数据分析模块的结果实现水质超标判 断、水质变化的原因追溯、风险评估及应急预案制定等功能; (3) 应用表现层: 又称为人机界面层,包含水质 时空分布状态以及变化趋势的实时展示、水质预警信息的实时推送、水质变化原因的智能分析、应急预案查 询等功能; 通过基于 Web Services 服务架构的人机界面访问接口, 实现 Web 版与 App 版湖库蓝藻立体监控 平台, 支持平台各个功能模块在平台前端界面上的可视化展示与人机交互.

\section{2 天一空一地立体监控系统巢湖实践}

巢湖 $\left(31.40^{\circ} \sim 31.72^{\circ} \mathrm{N}, 117.24^{\circ} \sim 117.90^{\circ} \mathrm{E}\right.$ ), 位于安徽省中部, 平均水深 $3.0 \mathrm{~m}$, 水面面积 $785.4 \mathrm{~km}^{2}$ ( 吴 淞 $9.0 \mathrm{~m}$ ), 流域面积 1.36 万 $\mathrm{km}^{2}$, 是中国著名的五大淡水湖之一. 沿湖共有人湖河流 39 条, 其中较大的河流 有杭埠河、白石天河、派河、南淝河、烔炀河、柘臮河、兆河等, 贡献了全湖总水量的 $90 \%{ }^{[11]}$,从南、西、北 3 面 汇人湖内, 然后在东南部经唯一的出湖河流裕溪河注人长江. 在 $1960 \mathrm{~s}$ 之前, 巢湖以其优美的风景以及丰富 的渔业资源而闻名 ${ }^{[12]}$. 然而, 由于当地, 特别是上游合肥市人口和经济的快速发展, 近几十年来该湖遭受了 富营养化和频繁的蓝藻水华暴发 ${ }^{[7,13-14]} .2012$ 年, 随着行政区划调整的完成, 巢湖成了合肥市内湖. 为更好 地组织协调环境污染治理和生态保护工作,更好地实现“拱卫长江下游生态安全”的重任,合肥市委、市政府 提出了“大湖名城、创新高地” 的城市发展规划. 2017 年, 我国环境保护部明确提出着力推进“老三湖” (太 湖、巢湖、滇池) 和“新三湖” (洱海、丹江口、白洋淀), 以及长江、海河、跨国界河流等流域水生态保护和水污 染防治. 巢湖作为“老三湖”之一, 构建天一空一地一体的监控系统和网络, 防止蓝藻水华突发性灾害, 不仅对 当地城市可持续发展和流域人民生产生活都具有重要作用,对于其他富营养化严重的湖库也具有较大借鉴 作用.

\section{1 监控手段建设}

水质参数监测传统上以人工采集回到实验室分析获得, 蓝藻水华面积以 MODIS 卫星监测为主. 人工监 测频率低, 覆盖范围有限, 出现突发情况很难觉察. 而 MODIS 卫星虽然时间分辨率很高, 但容易受云雨天气 影响. 据 2000-2019 年针对所有巢湖 MODIS 有效影像统计, 最好的年份也不超过 $150 \mathrm{~d}$ 有效影像, 这给日 常业务化监测蓝藻水华带来了难题; 另外, MODIS 影像空间分辨率在 $500 \mathrm{~m}$ 左右, 很难对重点区域, 比如取 水口、风景名胜区等进行有效观测. 这需要借助新的、成熟的观测手段弥补监测的缺位.

目前, 基于探头的水质自动观测技术突飞猛进,水站的监测频次可以根据情况连续监测或每几小时监 测一次, 管理人员可以通过控制软件自行设定, 自动、快速获取实测数据, 在突发性水污染事故预警预报监 测等方面有效弥补了人工监测的短板. 目前, 国家水质自动监测站的监测项目包括水温、 $\mathrm{pH}$ 值、溶解氧、电 导率、浊度、高锰酸盐指数、总有机碳、氨氮、总氮 (TN)、总磷 (TP) 和叶绿素 $a$ 等 ${ }^{[15]}$. 巢湖目前已经在湖体 7 个国控站点建成自动观测站, 主要观测 TN、TP、氨氮、化学需氧量、水温、叶绿素 $a$ 、溶解氧、pH 值和电导率 9 个参数. 另外, 沿湖岸带建成 33 个摄像头, 基本涵盖了主要人湖河口和重要风景名胜区, 可快速获取固定区 域的视频或者图像, 经过简单数据处理, 获取蓝藻水华的分布面积和范围 (图 2); 也可以进一步观测水色的 异常, 比如针对蓝藻水华堆积、死亡以及突发污染事件等引起的水色变化, 研制类似图 2 的自动处理算法和 程序, 实现水色异常自动报警.

无人机技术已经广泛应用于水体监测, 但能做到具体水质参数监测的主要是基于搭载高光谱传感器的 多旋翼等荷载量大的机型. 韩国科学家和中方合作, 已经有针对河流水体叶绿素 $a$ 和藻蓝素浓度无人机遥 感的成功案例 ${ }^{[16-17]}$. 但是, 高光谱传感器和能搭载其的多旋翼无人机等机型目前价格较高, 整套动轩在 60 万元以上; 特别是还涉及到复杂的飞行操控和数据处理, 直接应用到巢湖管理局等地方业务部门难度较大, 目前还不具备条件. 但是消费级无人机, 比如大疆精灵 Phantom 系列、御 Mavic 系列等, 价格在 1 万元左右, 成本可控, 且飞行经过简单培训很容易掌握, 可以快速获取较大范围的视频或者图像, 结合图 2 类似的图像 处理技术,可用于水源地取水口、风景名胜区和出人湖河流等重点区域的常规或者应急蓝藻监控.

\section{2 应急监控体系}

巢湖的应急监控体系主要围绕着“三三五”目标建设. 空间尺度从区域上划分为 3 个层次 (图 3 ) : 湖体、 重点区域和关键位置, 通俗地讲可以称为点、线、面. 由于空间尺度和关注问题的不同, 可以分别针对 3 个层 

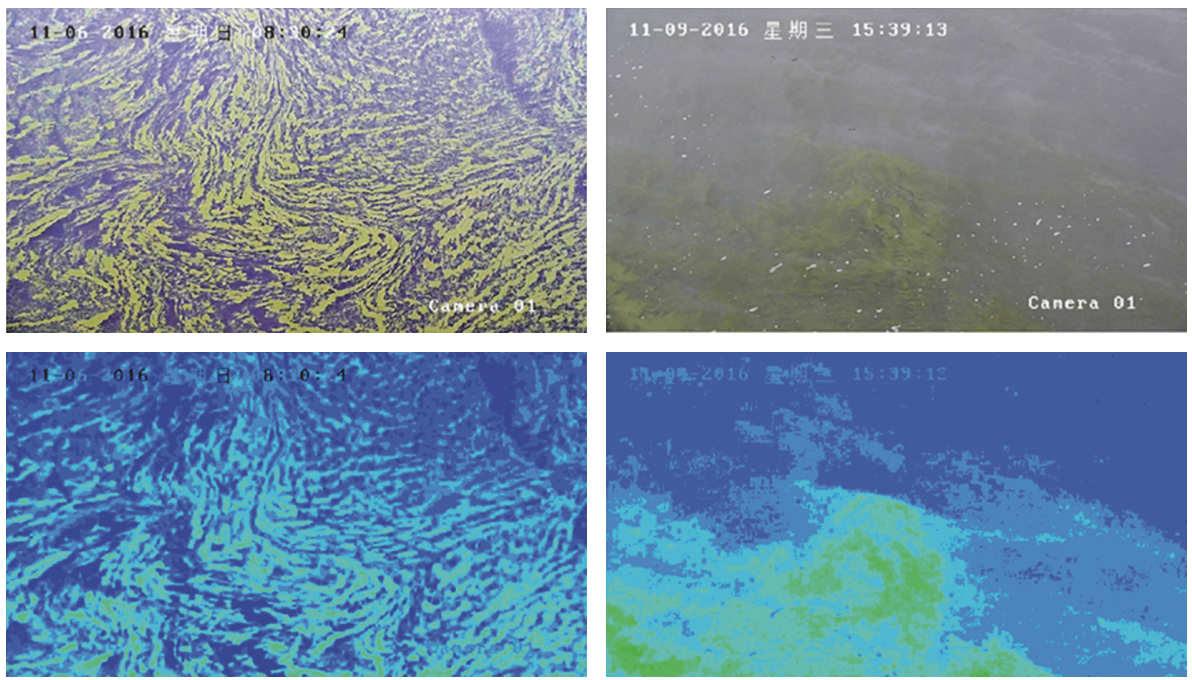

图 2 基于摄像头/无人机视频照片的蓝藻水华提取 (上行为原始照片,下行为蓝藻水华提取结果)

Fig. 2 Extraction of cyanobacterial blooms based on drone / camera photos ( upper row: original photos; lower row: cyanobacterial bloom extraction results)

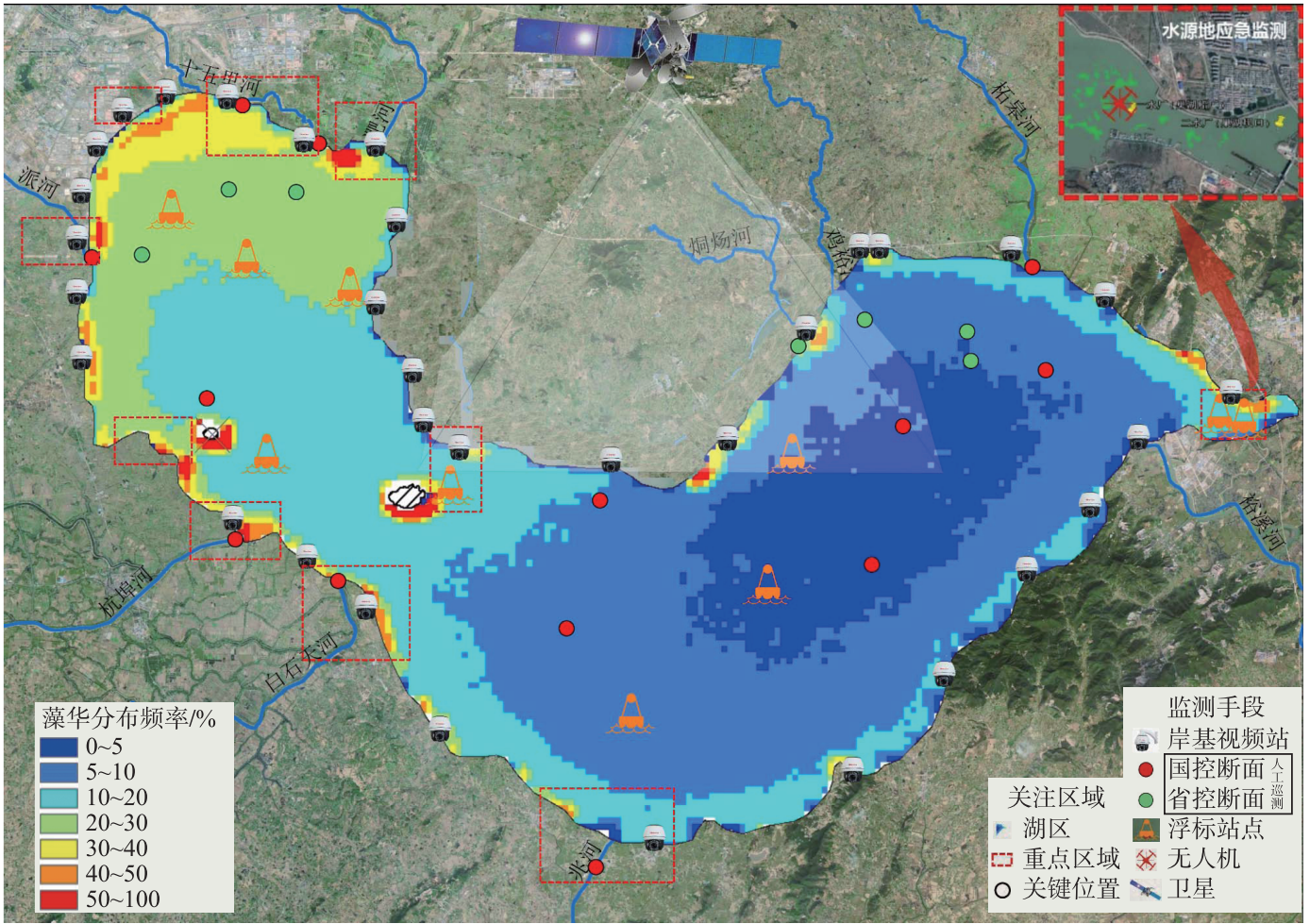

图 3 富营养化湖库天一空一地监控示意图 ( 以巢湖为例)

Fig.3 Schematic diagram of three-dimensional monitoring in eutrophic lakes (Take Lake Chaohu for example)

次采用不同的观测手段. 湖体 (面), 主要指整个巢湖水体, 区域大,主要面临的是蓝藻水华问题,卫星遥感高 频观测可以发挥主要监测作用; 重点区域 (线), 主要指人湖河口、风景名胜区、澡华暴发区、水源地 I 级保护 
区等, 面积一般较小, 可以主要采用高分辨率卫星数据观测, 并辅助以无人机和视频监测; 关键位置 (点), 主 要指水源地取水口、国控/省控断面、河流出人口断面、岸边带等, 区域非常小, 主要采用浮标自动监测、岸 基/平台视频监测, 辅助以无人机监测.

具体的建设方案如下 (表 1): (1) 整个湖体: MODIS、GOCI 等 $500 \mathrm{~m}$ 左右高频卫星观测数据(一天两次 或多次) 为主, 辅助以高分辨率卫星数据 (GF-1 WFI, $16 \mathrm{~m}$, 两天一次; Sentinel-2 MSI $10 \mathrm{~m}$, 单星 10 天一次, 双 星 5 天一次), 可获取蓝藻水华面积、叶绿素 $a$ 浓度等指标; (2) 重点区域 (河口、景观区、藻华暴发区、水源地 I 级保护区) : 以高分辨率卫星数据为主, 以无人机 (光学相机) 为辅, 可获取蓝藻水华面积、叶绿素 $a$ 浓度、污 染引起的黑水团范围和面积等指标. (3) 关键位置 (取水口、国控/省控断面、河流出人湖断面、岸边带等) : 以浮标自动监测、岸基/平台视频监测为主, 以无人机监测为辅; 浮标可获取精细的水质指标, 岸基/平台视 频和无人机可获取图片、视频, 提取蓝藻和黑水团等分布范围和面积.

表 1 天一空一地监控系统建设方案

Tab.1 Specific scheme of blooms monitoring platform

\begin{tabular}{|c|c|c|c|c|}
\hline 区域 & 监测现状及问题 & 手段和目标 & 获取指标 & 监测位置 \\
\hline 湖体 & $\begin{array}{l}\text { 主要依靠 MODIS 卫星数据, 云雨 } \\
\text { 天气无法获取有效数据 }\end{array}$ & $\begin{array}{l}\text { 辅助高分、高频卫星遥感数据, 增 } \\
\text { 加观测频次, 增加无人机观测 }\end{array}$ & $\begin{array}{l}\text { 蓝藻水华面积、叶绿 } \\
\text { 素 } a \text { 和藻蓝素浓度等 }\end{array}$ & 全湖 \\
\hline $\begin{array}{l}\text { 重点 } \\
\text { 区域 }\end{array}$ & $\begin{array}{l}\text { 目前缺乏有效监测手段, 无法及 } \\
\text { 时获知现状信息和突发污染状况 }\end{array}$ & $\begin{array}{l}\text { 以高分辨率卫星数据为主 } \\
\text { 配置无人机平台 (普通相机), 开 } \\
\text { 展应急监测 }\end{array}$ & $\begin{array}{l}\text { 蓝藻水华及黑水团分 } \\
\text { 布区域、面积; 叶绿素 } \\
a \text { 和藻蓝素浓度等 }\end{array}$ & $\begin{array}{l}11 \text { 条主要环湖河 } \\
\text { 流人湖口、中庙等 } \\
\text { 景观区、藻华易暴 } \\
\text { 发区、水源地 I级 } \\
\text { 保护区等 }\end{array}$ \\
\hline $\begin{array}{l}\text { 关键 } \\
\text { 位置 }\end{array}$ & $\begin{array}{l}\text { 目前主要是人工巡测, 周期长, 无 } \\
\text { 法及时获知现状信息和突发污染 } \\
\text { 状况 }\end{array}$ & $\begin{array}{l}\text { 设置岸基视频监测平台, 对环湖 } \\
\text { 河道人湖口等开展全方位、高时 } \\
\text { 频动态监测, 并对突发污染及污 } \\
\text { 染超标事件发出及时报警 } \\
\text { 湖体部分站点设置固定浮标, 对 } \\
\text { 水质开展实时监测和及时传输, } \\
\text { 当水质超出标准时, 进行报警 } \\
\text { 配置无人机, 对关键位置进行应 } \\
\text { 急监测 }\end{array}$ & $\begin{array}{l}\text { 水温、pH 值、透明度、 } \\
\text { 溶解氧、高锰酸盐指 } \\
\text { 数、生化需氧量、氨 } \\
\text { 氮、TN、TP、叶绿素 } a \text { 、 } \\
\text { 化学需氧量; 蓝藻水 } \\
\text { 华及黑水团分布区 } \\
\text { 域、面积等 }\end{array}$ & $\begin{array}{l}\text { 取水口、国控/省 } \\
\text { 控断面、河流出人 } \\
\text { 湖断面、岸边带等 }\end{array}$ \\
\hline
\end{tabular}

应急监控系统功能, 主要包括 3 个部分: 异常报警、应急监测和综合服务. 异常报警, 主要利用常规监测 手段发现异常, 并通过系统自动报警发送给相关负责人;应急监测, 在接到异常报警后, 启动应急监测, 实现 异常区域快速监测和数据处理; 综合服务, 主要是发布监测报告, 提供原因分析, 制定应急处置方案, 为政府 相关管理机构科学决策服务. 具体任务: (1) 异常报警: 针对蓝藻水华暴发面积大、水质指标超标和突发水污 染事件等, 利用常规监测手段发现异常并报警. 湖体和重点区域蓝藻水华监测以卫星为主, 面积大于一定阈 值时, 自动触发报警; 重点区域和关键位置, 以浮标自动监测、岸基/平台视频监测为主, 浮标水质指标超过 一定阈值, 岸基/平台视频发现水色异常, 自动触发报警. (2) 应急监测 : 接到异常报警通知后, 启动无人机和 人工监测等手段, 实现异常区域高频率监测, 并能对监测数据快速处理, 及时获取全面情况和相关水质信息. (3) 综合服务: 构建软硬件结合的大数据平台, 快速获取和发布相关监测结果; 综合多种监测手段, 比对历史 数据,揭示水华、水质异常和突发水污染事件原因; 制定不同情景方案, 提供应急处置建议.

\section{3 业务流程}

监测手段可以划分为日常监测和应急监控两种. 日常监测主要采用卫星遥感、浮标、岸基/平台视频等 不需要人工操作、可自动连续的监测手段; 应急监控手段主要采用无人机和人工监测, 其中无人机主要是大 疆等消费级机型, 获取视频和照片, 需要根据人工指令启动. 具体的工作流程为 (图 4): (1) 对水华面积、水 色异常、水质指标超标等设置阈值; (2) 基于日常监测手段,对全湖和重点区域水华聚集、水色异常和突发水 污染事件等监测, 超过阈值后自动或者人工复合后报警, 并通过 APP 推送、短信等形式到达指定责任人; 
(3) 责任人采取措施,启动无人机和人工监测等应急监测.

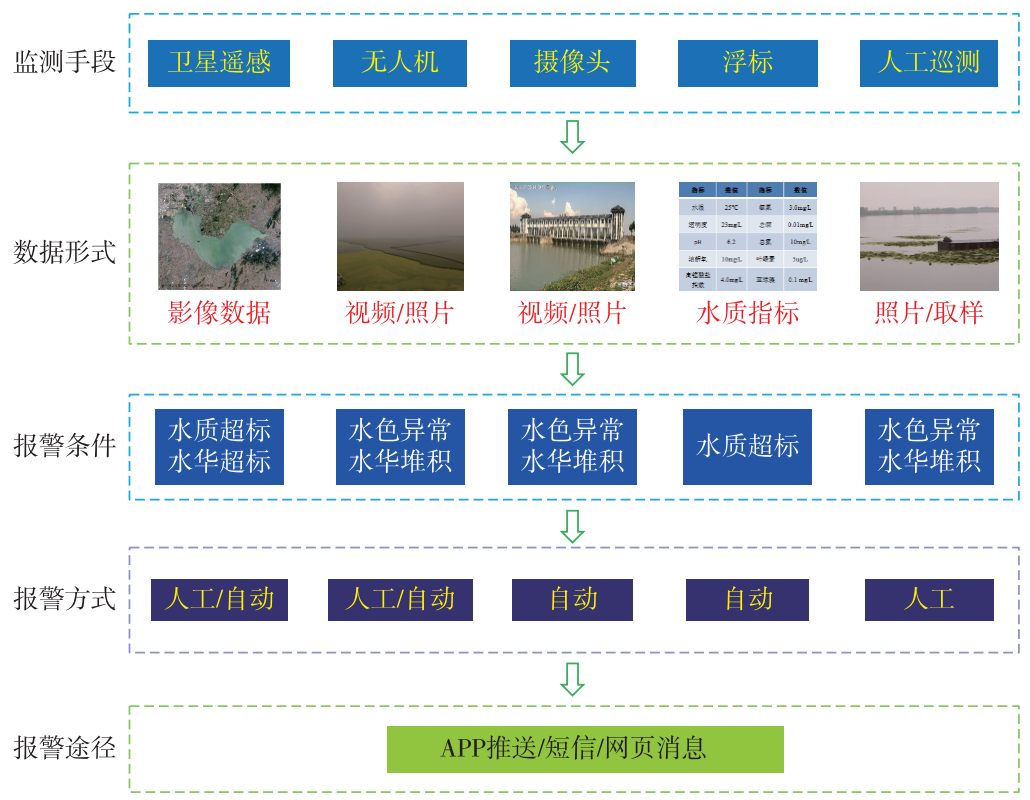

图 4 天一空一地立体监控体系业务流程

Fig.4 Work flow of the blooms monitoring system

\section{3 问题与挑战}

\section{1 不同观测手段优缺点和互补性}

巢湖、太湖等大型湖泊蓝藻水华卫星遥感现在采用的多是以 MODIS 传感器为主的约 $500 \mathrm{~m}$ 分辨率数 据, 其优势是 Terra 和 Aqua 两颗星配合, 可以上午(约 11:00) 和下午(约 13:30) 重复观测,且数据免费,容易 获取,水华提取和叶绿素 $a$ 估算等算法较为成熟. 缺点主要包括两方面:一方面是空间分辨率较粗, 小范围 的重点观测区域无法有效监测; 另一方面是光学数据的共有缺陷, 受云雨天气影响较大, 在江淮流域全年有 效数据基本不到一半; 高分辨率卫星可以实现重点区域观测, 但数量有限, 在巢湖的实践表明, 目前有效数 据 1 周不超过 1 景. 无人机可以部分弥补这个缺陷, 通过针对重点区域拍摄, 可以快速获取影像, 了解水环 境情况; 也可以在有云情况下补充数据. 但无人机同样存在缺陷, 主要是拍摄需要人工携带和启动, 无法做 到类似卫星的自主拍摄, 且风雨天气受限较多, 多用于人工常规巡测或者应急观测. 设置在固定站点的摄像 头可以做到白天连续观测, 通过结合算法实现自动提取, 可以弥补重点位置卫星和无人机观测不足的问题. 实际上, 不管是卫星遥感、无人机还是摄像头, 都依赖光学镜头, 存在不利天气和水化学指标无法观测的问 题 (表 2). 自动浮标有效弥补了这个缺陷, 可以监测 TN、TP 浓度等水化学指标, 特别是可以连续观测, 不受 天气影响, 但由于购买和维护成本较高, 只在有限点位安装. 人工巡测是最为传统的观测方式, 更多的是弥 补现有观测手段不足的问题. 总体来说, 卫星遥感、摄像头和浮标等具有自动和连续观测能力的技术, 应该 是监测水环境灾害突发事件并及时报警的主要观测方式; 其中,卫星遥感主要针对全湖或重点区域大面积 水华或黑水团, 而摄像头主要针对局部区域水华或黑水团, 自动监测站则是国控/省控等固定站点的水质指 标, 三者具有很强的互补性, 可以发挥协同作用. 而无人机、人工监测更多地用于事件应急观测, 补充突发事 件发生时某些区域没有影像、水质超标没有数据的缺陷. 因此, 充分发挥各种手段的优势, 弥补相对劣势, 在 日常监测、异常报警和应急防控 3 方面做到不同时空尺度的信息融合, 有助于更好地满足湖泊水环境监测 的需求. 
表 2 不同监测手段优缺点比较

Tab.2 Comparison of advantages and disadvantages of different monitoring methods

\begin{tabular}{|c|c|c|c|c|}
\hline 手段 & 范围 & 观测时间 & 观测参数 & 优缺点 \\
\hline 卫星遥感 & 全湖 & $\begin{array}{l}\diamond \text { MODIS: } 1 \text { 天 } 2 \text { 次 } \\
\diamond \text { 高分卫星: } 2 \sim 3 \text { 天 } 1 \text { 次 }\end{array}$ & $\begin{array}{l}\diamond \text { 水华、黑水团、叶绿素 } a \text { 、藻 } \\
\text { 蓝素等 }\end{array}$ & $\begin{array}{l}\diamond \text { 大范围、周期性和长时间序列 } \\
\text { 数据 } \\
\text { 〉不能保证每天有数据 } \\
\text { 〉观测指标有限, 欠缺关心的 } \\
\text { TN、TP、溶解氧等水质指标 }\end{array}$ \\
\hline 无人机 & 重点区域 & $\begin{array}{l}\diamond \text { 人工安排 } \\
\diamond \text { 随机机动 }\end{array}$ & 〉水华、黑水团、水色变化 & $\begin{array}{l}\diamond \text { 机动灵活, 分辨率高 } \\
\diamond \text { 不能自动作业 } \\
\diamond \text { 观测指标有限 (同卫星) }\end{array}$ \\
\hline 摄像头 & 重点位置 & $\begin{array}{l}\diamond \text { 白天连续观测 } \\
\diamond \text { 弱光和夜晚无法观测 }\end{array}$ & $\diamond$ 水华、黑水团、水色变化 & $\begin{array}{l}\diamond \text { 连续观测 } \\
\diamond \text { 固定位置, 无法移动, 观测视 } \\
\quad \text { 角有限 } \\
\diamond \text { 观测指标有限( 同卫星) }\end{array}$ \\
\hline 浮标 & 重点位置 & $\diamond 24 \mathrm{~h}$ 连续观测 & $\begin{array}{l}\diamond \mathrm{TN} 、 \mathrm{TP} 、 \text { 氨氮、化学需氧量、 } \\
\text { 水温、叶绿素 } a \text { 、溶解氧、 } \mathrm{pH} \text { 、 } \\
\text { 电导率等 }\end{array}$ & $\begin{array}{l}\diamond \text { 连续观测, 指标多 } \\
\diamond \text { 成本较高、有限点位 } \\
\diamond \text { 与实验室分析数据需要人工 } \\
\text { 校正 }\end{array}$ \\
\hline 人工 & $\begin{array}{l}\text { 重点区域 } \\
\text { 重点位置 }\end{array}$ & $\begin{array}{l}\diamond 人 工 \text { 安排 } \\
\diamond \text { 随机机动 }\end{array}$ & 〉采集水样观测, 指标可选 & $\begin{array}{l}\diamond \text { 成本高 } \\
\diamond \text { 观测数量和时间有限 }\end{array}$ \\
\hline
\end{tabular}

\section{2 未来发展趋势}

卫星遥感一直在湖泊等内陆水体监测方面发挥着不可替代的作用. 随着目前卫星数据源越来越多, 比 如我国的高分系列和海洋系列等卫星、欧盟的哨兵 ( sentinel) 系列卫星、美国的 NPP-VIIRS 等卫星以及韩国 的 GOCI 静止卫星, 可选择和采用的数据非常丰富, 空间分辨率也有显著提高. 但遗憾的是, 现有卫星设计主 要是针对陆地或者海洋, 并没有针对湖泊等内陆水体的遥感卫星, 存在高时间分辨率数据空间分辨率低、高 空间分辨率数据时间分辨率低以及绝大部分传感器性能并不完全适合湖泊水体特别是水源地监测等缺点. 在现有条件下, 可以加强多星联合监测的研究, 满足当前的需要. 但是随着未来卫星等荷载研制和发射成本 的降低, 更需要专门设计针对湖泊的专用传感器和荷载, 特别是静止卫星, 或者小卫星集群, 甚至航空气球, 充分发挥卫星大范围、周期性的特点, 研制高空间分辨率 ( 优于 $50 \mathrm{~m}$ )、高时间分辨率 (一天至少大于两次观 测) 以及适合水体特点的波段和高信噪比的传感器, 满足湖泊观测的需要. 无人机在某种程度上弥补了卫星 遥感的缺陷, 可以针对小范围区域进行快速监测, 但目前无人机受制于载重和传感器的限制, 更多的还是用 于拍照或者录像. 虽然高光谱传感器等已经成熟, 但成本高昂, 数据处理复杂, 目前离业务化运行还有段距 离. 未来随着传感器小型化和性能提升, 无人机续航能力加强, 数据快速处理能力显著提高, 必将在水环境 监测领域发挥关键作用, 最终希望达到所见即所得的理想效果, 即飞机飞过水体, 水质自动成像, 我们看到 的不再是单纯的影像数据, 而是直接显示关注的水质浓度信息. 摄像头与无人机相似,一个在天上机动飞 行, 一个在固定点位进行连续观测, 目前更多起到的作用都是图像监测, 获取的主要是定性信息 (部分通过 提取其中的水华或者水体颜色尝试定量化), 未来如果随着多光谱、甚至高光谱传感器的发展, 如果岸基视 频监控发展成岸基高光谱成像监控, 也将和无人机一样, 实现从定性到定量的突破, 将显著提高观测能力, 有望发展成全息扫描系统, 通过连续的成像光谱观测, 实现水质的连续观测. 自动浮标是未来最有望实现突 破的技术, 目前自动观测的主要问题是探头成本, 特别是维护成本较高, 耗费大量的人力物力, 而且部分探 头需要配置的外设装置较大, 站点和观测参数都有限, 数据质量不稳定, 未来应该围绕探头小型化、自动化、 易维护、高性能目标发展, 满足湖泊水质更多的观测要求. 最为重要的是, 未来需要结合大数据和云计算等 技术, 把各种观测手段获取的信息有效整合, 从数据的展示发展到数据的智慧管理, 为湖泊水环境灾害监控 和应急预警服务. 


\section{4 结论}

本文针对富营养化湖库富营养化引起的蓝藻水华监测应急问题,基于目前成熟的卫星、无人机、岸基/ 平台视频、浮标、人工巡测等技术或手段,提出了天一空一地一体化监控系统的建设目标、系统框架和工作流 程, 并在巢湖进行应用实践,已取得初步成效. 相信这一套系统框架不仅在巢湖,而且在更多的富营养化湖 库都具有应用和推广价值. 同时, 需要注意的是, 目前的监测手段主要局限于现有成熟的、可业务化运行的 技术, 还未做到全天候全要素定量监测, 未来随着类似高光谱无人机等更多手段的成熟以及更多新技术手 段的出现,相信天一空一地立体监控系统将更为完善,更好地满足富营养化湖库蓝藻水华监控的要求.

\section{5 参考文献}

[ 1 ] Yang GS, Ma RH, Zhang L et al. Lake status, major problems and protection strategy in China. J Lake Sci, 2010,22 (6) : 799-810. DOI: 10.18307/2010.0601. [杨桂山, 马荣华, 张路等. 中国湖泊现状及面临的重大问题与保护策 略. 湖泊科学, 2010, 22(6) : 799-810.]

[ 2 ] Nanjing Institute of Geography and Limnology, Chinese Academy of Sciences. On the cause of cyanophyta bloom and pollution in water intake area and emergency measures in Meiliang Bay, Lake Taihu in 2007. J Lake Sci, 2007, 19(4) : 357 358. DOI: $10.18307 / 2007.0401$. [中国科学院南京地理与湖泊研究所. 太湖梅梁湾 2007 年蓝藻水华形成及取水口 污水团成因分析与应急措施建议. 湖泊科学, 2007, 19(4): 357-358.]

[ 3 ] Qin BQ, Paerl HW, Brookes JD et al. Why Lake Taihu continues to be plagued with cyanobacterial blooms through 10 years (2007-2017) efforts. Science Bulletin, 2019, 64(6) : 354-356. DOI: 10.1016/j.scib.2019.02.008.

[ 4 ] Zhu GW, Zou W, Guo CX et al. Long-term variations of phosphorus concentration and capacity in Lake Taihu, 20052018: Implications for future phosphorus reduction target management. J Lake Sci, 2020, 32(1) : 21-35. DOI: 10.18307/ 2020.0103. [ 朱广伟, 邹伟, 国超旋等. 太湖水体磷浓度与赋存量长期变化(2005-2018 年) 及其对未来磷控制目 标管理的启示. 湖泊科学, 2020, 32(1) : 21-35.]

[ 5 ] Xu H, Paerl HW, Qin B et al. Determining critical nutrient thresholds needed to control harmful cyanobacterial blooms in eutrophic lake Taihu, China. Environmental Science \& Technology, 2015, 49(2) : 1051-1059. DOI: 10.1021/es503744q.

[ 6 ] Duan HT, Loiselle SA, Zhu L et al. Distribution and incidence of algal blooms in Lake Taihu. Aquatic Sciences, 2015,77 (1) : 9-16. DOI: 10.1007/s00027-014-0367-2.

[ 7 ] Duan HT, Tao M, Loiselle SA et al. MODIS observations of cyanobacterial risks in a eutrophic lake: Implications for longterm safety evaluation in drinking-water source. Water Research, 2017, 122: 455-470. DOI: 10.1016/j. watres. 2017. 06.022 .

[ 8 ] Wang JH, He L, Yang C et al. Comparison of algal bloom related meteorological and water quality factors and algal bloom conditions among Lakes Taihu, Chaohu, and Dianchi(1981-2015). J Lake Sci, 2018, 30 (4) : 897-906. DOI: 10. 18307/2018.0403. [王菁晗, 何吕奇姝, 杨成等. 太湖、巢湖、滇池水华与相关气象、水质因子及其响应的比较 (1981-2015 年). 湖泊科学, 2018, 30(4) : 897-906.]

[ 9 ] Shao Y, Zhao ZM, Huang FX et al. Precise emergency service system construction and demonstration through synergy observation of spaceborne, airborne, and ground remote sensing. Journal of Remote Sensing, 2016, 20 ( 6) : 1485-1490. DOI : 10.11834/jrs.20166368. [邵芸, 赵忠明, 黄富祥等. 天空地协同遥感监测精准应急服务体系构建与示范. 遥 感学报, 2016, 20(6): 1485-1490.]

[10] Wu WB, Shi Y, Zhou QB et al. Framework and recommendation for constructing the SAGI digital agriculture system. Smart Agriculture, 2019，(2): 64-72. DOI: 10.12133/j.smartag.2019.1.2.201812-SA021. [吴文斌, 史云, 周清波等. 天空地数字农业管理系统框架设计与构建建议. 智慧农业, 2019, (2) : 64-72.]

[11] Yang LB, Lei K, Meng W et al. Temporal and spatial changes in nutrients and chlorophyll- $\alpha$ in a shallow lake, Lake Chaohu, China: An 11-year investigation. Journal of Environmental Sciences, 2013, 25 (6) : 1117-1123. DOI: 10.1016/ S1001-0742 ( 12) 60171-5.

[12] Xu FL. Exergy and structural exergy as ecological indicators for the development state of the Lake Chaohu ecosystem. Ecological Modelling, 1997, 99(1) : 41-49. DOI: 10.1016/s0304-3800(96)01921-7.

[13] Kong XZ, Jørgensen SE, He W et al. Predicting the restoration effects by a structural dynamic approach in Lake Chaohu, 
China. Ecological Modelling, 2013, 266: 73-85. DOI: 10.1016/j.ecolmodel.2013.07.001.

[14] Zhang YC, Ma RH, Zhang M et al. Fourteen-year record (2000-2013) of the spatial and temporal dynamics of floating algae blooms in lake Chaohu, observed from time series of MODIS images. Remote Sensing, 2015, 7 ( 8) : 10523-10542. DOI: $10.3390 / \mathrm{rs} 70810523$.

[15] Liu J, Zhou M, Chen X et al. Study on the construction and management of the quality automatic monitoring network of state surface water. Environmental Monitoring and Forewarning, 2014, 6(1): 10-13. [刘京, 周密, 陈金等. 国家地表 水水质自动监测网建设与运行管理的探索与思考. 环境监控与预警, 2014, 6(1): 10-13.]

[16] Kwon YS, Pyo J, Kwon YH et al. Drone-based hyperspectral remote sensing of cyanobacteria using vertical cumulative pigment concentration in a deep reservoir. Remote Sensing of Environment, 2020, 236: 111517. DOI: 10. 1016/j. rse. 2019.111517.

[17] Pyo J, Duan HT, Baek S et al. A convolutional neural network regression for quantifying cyanobacteria using hyperspectral imagery. Remote Sensing of Environment, 2019, 233 : 111350. DOI: 10.1016/j.rse.2019.111350. 